\title{
ASSESSMENT OF THE QUALITY OF LIFE IN ELDERLY PATIENTS WITH OSTEOARTHRITIS DURING THE TREATMENT OF CHRONIC PAIN WITH TRANSDERMAL BUPRENORPHINE
}

\author{
MAREK WIDENKA ${ }^{1,2}$ and WOJCIECH LEPPERT ${ }^{3,4 *}$ \\ 'Department of Geriatrics Regional Hospital, Ostrow Wielkopolski, Poland \\ ${ }^{2}$ Non Public Palliative Medicine Home Hospice, Kalisz, Poland \\ ${ }^{3}$ Department of Palliative Medicine, Institute of Medical Sciences, Collegium Medicum, \\ University of Zielona Góra, Zielona Góra, Poland \\ ${ }^{4}$ Department of Palliative Medicine Poznan University of Medical Sciences, Poznań, Poland
}

\begin{abstract}
The aim of the study was to evaluate the quality of life of elderly patients diagnosed with osteoarthritis during treatment of chronic pain with transdermal buprenorphine. Transdermal buprenorphine was used for 10 days in 60 patients over 64 years old randomly assigned to 3 groups with starting doses $8.75 \mu \mathrm{g} / \mathrm{h}$ (group 1), $17.5 \mu \mathrm{g} / \mathrm{h}$ (group 2), and $35 \mu \mathrm{g} / \mathrm{h}$ (group 3). The severity of pain, fatigue, drowsiness, nausea, vomiting, constipation, lack of appetite, shortness of breath, depression, anxiety, well-being and another symptom reported by patients were evaluated every day with the Edmonton Symptom Assessment System-revised (ESAS-r). At baseline depressive disorders were assessed by the Geriatric Depression Scale. Lower initial doses $(8.75 \mu \mathrm{g} / \mathrm{h}$ and $17.5 \mu \mathrm{g} / \mathrm{h})$ were better tolerated compared to $35 \mu \mathrm{g} / \mathrm{h}$. Drowsiness, confusion, and vomiting occurred less frequently in patients treated with lower initial doses $(8.75 \mu \mathrm{g} / \mathrm{h}, 17.5 \mu \mathrm{g} / \mathrm{h})$ compared to patients treated with starting dose of $35 \mu \mathrm{g} / \mathrm{h}$. A reduction of the intensity of pain, fatigue, drowsiness, lack of appetite, depression, anxiety, and well-being, without differences between patient groups was observed, although nausea and vomiting did not improve. Three patients in group 1 reported diarrhea, 2 patients in group 2 had diarrhea and itching, and 3 patients in group 3 had diarrhea, itching, and dizziness. Transdermal buprenorphine provided effective analgesia regardless of the starting dose of the drug. The treatment of elderly patients with chronic pain of severe intensity induced by osteoarthritis with transdermal buprenorphine resulted in an improved patients' quality of life with respect to symptoms and performance status. Lower initial doses of transdermal buprenorphine $(8.75 \mu \mathrm{g} / \mathrm{h}$ and $17.5 \mu \mathrm{g} / \mathrm{h}$ ) were associated with less adverse effects.
\end{abstract}

Keywords: adverse effects, analgesia, pain, quality of life, transdermal buprenorphine

The prevalence of chronic pain increases with age. It has been described in $50-70 \%$ of the elderly $(1,2)$. One of the most common causes of non-cancer pain in the elderly is osteoarthritis. Over $70 \%$ of patients hospitalized in geriatric departments suffer from osteoarthritis (3). There is a direct correlation between intensifying pain and the deterioration of cognitive functions, depressive and anxiety disorders, and sleep disorders. The coexistence of chronic pain leads to the deterioration of the quality of life and functional performance, undernutrition, and an increased risk of falls, which in turn results in the deterioration of social relationships $(4,5)$. A multidimensional impact of pain results in greater vulnerability and less efficient responses to various stressors by the elderly, which contributes to the development of the frailty syndrome (6). Considering a bio-psycho-social-spiritual model of pain, proper treatment should take into account multidirectional interventions (7). There are many treatment methods of pain with proven effectiveness available as potential therapeutic interventions in elderly patients, relying, but not exclusively, on analgesics as well as numerous non-pharmacology techniques and interventional treatment (8).

Nevertheless, treatment of chronic pain is frequently inadequate in the elderly (9). In a retrospective, multicenter study of elderly patients with pain staying in 24-hour care centers, $38 \%$ of patients between 65 and 74 years old received pain treatment, and in the group of patients over 84 years old - 13\% of them (10). On one hand, this results from the fact that effective treatment of pain in this population of patients is limited because of physiological changes

* Corresponding author: e-mail: wojciechleppert@wp.pl 
affecting metabolism, a higher risk of the occurrence of adverse effects of analgesics and other drugs, frequent comorbidities, including cognitive dysfunction, and polypharmacy (11).

On the other hand, opioidophobia observed among patients and their families, as well as medical staff constitutes an obstacle to effective treatment of chronic pain of severe intensity, which is 6-10 in the NRS (Numerical Rating Scale) (12). Meanwhile, opioid analgesics can be an effective method of managing intense chronic pain and are also recommended for elderly patients as a part of a complex therapeutic strategy (5). Scientific reports on adverse effects associated with the use of opioids in pain management in the elderly are inconclusive (13). It has been stressed, however, that in patients suffering from severe pain, potentially harmful effects of opioids, particularly with respect to cognitive functions, are compensated by an improvement of general performance status associated with adequate pain treatment (14). The aim of the study was to evaluate analgesia and additional symptoms, i.e. tiredness, drowsiness, nausea, vomiting, constipation, appetite, shortness of breath, depression, anxiety, and wellbeing during the treatment of chronic pain of severe intensity $(\mathrm{NRS}>5)$ with transdermal buprenorphine in elderly patients diagnosed with degenerative joint disease, hospitalized in a Department of Geriatrics.

\section{PATIENTS AND METHODS}

The study was conducted in patients over 64 years old, hospitalized in the Department of Geriatrics, and diagnosed with chronic pain of severe intensity $(\mathrm{NRS}>5$ ) caused by osteoarthritis. The duration of the study was 10 days.

The Edmonton Symptom Assessment Systemrevised (ESAS-r) was used every day in order to evaluate the severity of current symptoms, i.e. pain, fatigue, drowsiness, nausea, vomiting, constipation, lack of appetite, shortness of breath, depression, anxiety, well-being and other symptoms not mentioned in the questionnaire (15). Also, the Geriatric Depression Scale (GDS) was used on the first day of the study (16). ESAS-r was used every day in order to evaluate the severity of the aforementioned symptoms, on a scale from 0 to 10 where 0 indicates no symptom or the best well-being, and 10 indicates worst symptom intensity or the worst possible well-being.

The Geriatric Depression Scale-Short Form (GDS-SF), consisting of 15 closed questions, was

Figure 1.

Flowchart of the study.

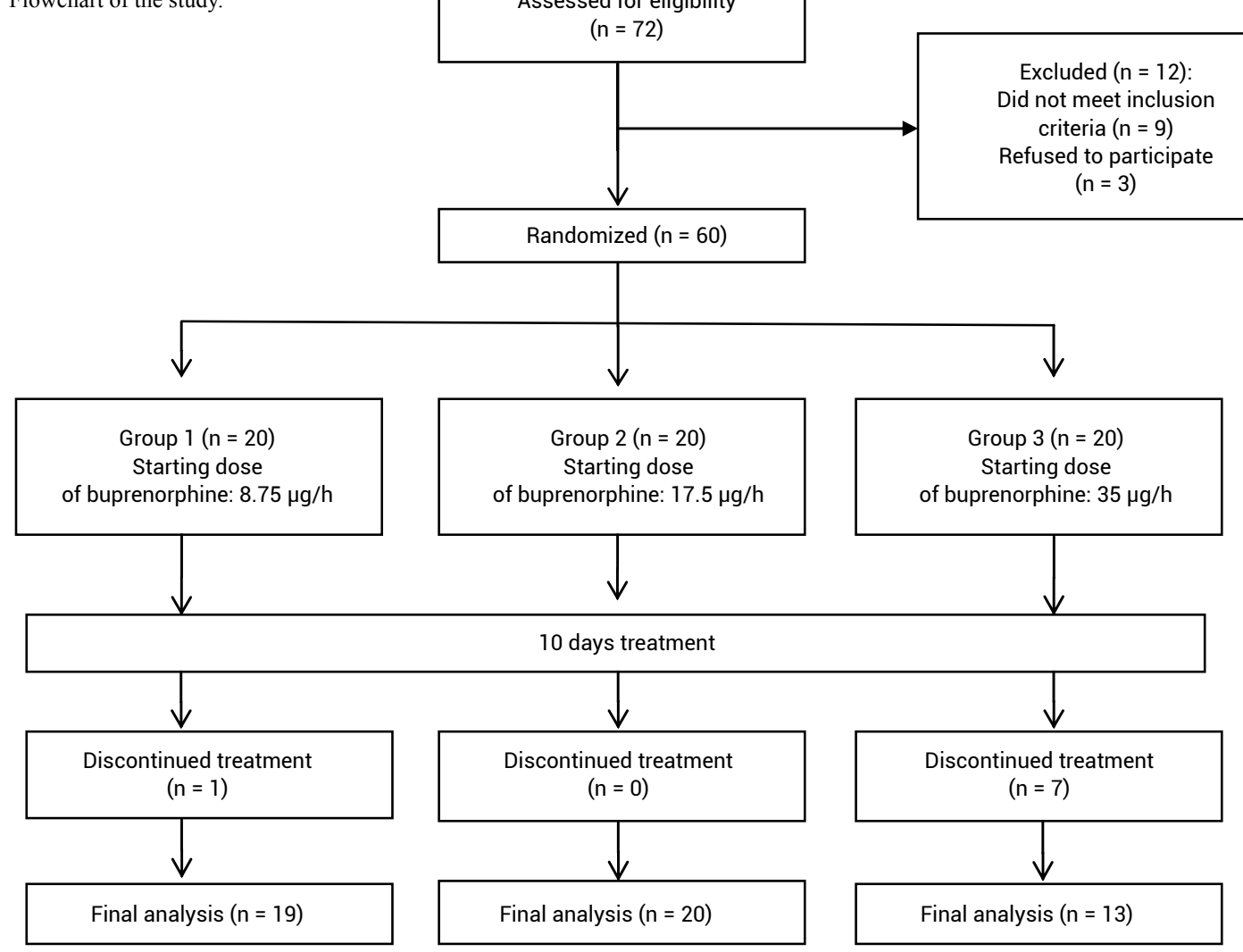


used in the present study. The answers scored either 0 or 1 point. The scoring for GDF-SF is as follows: 0-5 points - normal; $6-10$ points - mild depression; 11-15 points - severe depression. The points of intersection presented above guarantee optimal sensitivity (84\%) and specificity (95\%) of the scale (16).

Sixty patients participated in the study (Figure 1). The patients were randomly assigned to one of the three groups of 20 people (block randomization). In group 1, a starting dose for the treatment was $8.75 \mu \mathrm{g} / \mathrm{h}$, in group $2-17.5 \mu \mathrm{g} / \mathrm{h}$, and in group 3-35 $\mu \mathrm{g} / \mathrm{h}$. Transdermal buprenorphine was used every 72 hours with the possibility of increasing the dose every 48 hours, every 60 hours, or every 72 hours.

The doses of buprenorphine were increased until successful analgesia (NRS $\leq 4$ ) and an acceptable intensity of adverse effects were achieved according to the scheme:

Group 1: $8.75 \mu \mathrm{g} / \mathrm{h} \rightarrow 17.5 \mu \mathrm{g} / \mathrm{h} \rightarrow 35 \mu \mathrm{g} / \mathrm{h} \rightarrow$ $\rightarrow 52.5 \mu \mathrm{g} / \mathrm{h} \rightarrow 70 \mu \mathrm{g} / \mathrm{h}$

Group 2: $17.5 \mu \mathrm{g} / \mathrm{h} \rightarrow 35 \mu \mathrm{g} / \mathrm{h} \rightarrow 52.5 \mu \mathrm{g} / \mathrm{h} \rightarrow 70 \mu \mathrm{g} / \mathrm{h}$ Group 3: $35 \mu \mathrm{g} / \mathrm{h} \rightarrow 52.5 \mu \mathrm{g} / \mathrm{h} \rightarrow 70 \mu \mathrm{g} / \mathrm{h}$

In order to obtain starting doses of $17.5 \mu \mathrm{g} / \mathrm{h}$ and $8.75 \mu \mathrm{g} / \mathrm{h}$, a patch of $35 \mu \mathrm{g} / \mathrm{h}$ was divided into 2 and 4 equal parts, respectively. In cases where satisfactory pain relief was not achieved $(\mathrm{NRS}>4)$ and/or severe adverse effects occurred, and/or patients resigned, the study was discontinued. In the treatment of breakthrough pain, buprenorphine sublingual tablets were used as a single dose of $0.2 \mathrm{mg}$. Patients could continue previously recommended adjuvant analgesics, and the medicines and doses used were not changed during the study. All patients were administered lactulose at the dose of $20 \mathrm{~g}$ per day for the prevention of constipation. In case of lactulose intolerance, macrogol at the dose of $10 \mathrm{~g}$ per day was administered. If constipation occurred despite preventive treatment implemented, glycerin suppository (on day 2 in the absence of stool) and an enema (on day 3 in the absence of stool) were additionally used. Antiemetics were not used as prophylaxis.

Pain at its worst and pain on the average assessed by NRS was used in order to qualify patients for the study on day 1 and in order to monitor pain management in the following days. Patients qualified for the study did not have cognitive disorders and dementia (MMSE score $>23$ points). Patients excluded from the study were: patients less than 65 years old, patients without pain or with pain $\leq 5$ in the NRS scale, patients with cognitive dysfunction and dementia (MMSE $<24$ points), patients with at least double elevated normal levels of aminotransferase and bilirubin, cancer diagnosis, patients previously treated with buprenorphine and/or other opioids from the third step of the WHO analgesic ladder who could not be administered medicines sublingually and transdermally. Patients excluded from the study were also: patients with hypersensitivity to buprenorphine and/or any other excipient, patients with opioid dependence and opioid withdrawal syndrome, patients with present or potential respiratory failure, patients treated with monoamine oxidase (MAO) inhibitors within the last 14 days, and patients diagnosed with muscle fatigue. The study protocol was approved by the Bioethics Committee of the Regional Medical Council of the Wielkopolska (Great Poland) Chamber of Physicians and Dentists in Poznań (consent number 14/2016).

\section{Statistical analysis}

The data obtained in the study were analyzed statistically with the data analysis software system Statistics, version 13. A statistical description of quantitative variables was created with the use of measures of central tendency - the arithmetical mean, and dispersion with the use of a standard deviation. Qualitative variables were expressed with numbers and percentages. Statistical inference was conducted with the use of parametric tests after prior checking of data distribution. The data was expressed on the interval scale (the results of the questionnaires) and obtained with the use of standard research tools and the data distribution did not deviate far from a normal distribution (the analysis of variance was used - ANOVA). Repeated measures analysis of variance was used to examine the dynamics of variables. The significance level was set at 0.05 to establish criteria for the rejection of the null hypothesis in all verifications of hypotheses.

\section{RESULTS}

The mean age of patients was 81.6 years (range 67-95 years). Thirteen men (21.67\%) and 47 women (78.33\%) were enrolled in the study, 17 (28.33\%) living in villages and $43(71.67 \%)$ in cities. A total of 5.7 concurrent diseases per patient were diagnosed, most frequent being cardiovascular diseases in 52 (86.6\%) patients, type 2 diabetes in $22(36.6 \%)$ patients, and chronic kidney disease in 21 (35\%) patients. At baseline non-steroidal anti-inflammatory drugs (NSAIDs) in $46(76.6 \%)$ patients, paracetamol in $35(58.3 \%)$ patients, tramadol in $27(45 \%)$ patients and metamizole in $8(13.3 \%)$ patients were most 
frequently used analgesics. A total of 33 (55\%) patients took analgesics irregularly (as needed or not according to prescription), and 4 (6.6\%) of patients did not use pain medications. Among patients treated with NSAIDs, 19 (31.6\%) patients took 2 or more NSAIDs concurrently, and 36 (78.3\%) patients had contraindications to NSAIDs according to Summary of Product Characteristics (SPC). The pain was usually located in several joints (an average of 4.3 joints per patient) and most frequently located in the spine in $51(85 \%)$ patients, knee joints in $39(65 \%)$ patients, and hip joints in $36(60 \%)$ patients. The mean final dose of transdermal buprenorphine in all the patients was $28.6 \mu \mathrm{g} / \mathrm{h}$. A mean dose of sublingual buprenorphine per patient was $0.48 \mathrm{mg}$ during the whole study period (Table 1).
A change of a buprenorphine patch was required because of pain in 6 patients in group $1(35 \%)$, in 5 patients in group $2(25 \%)$, and 4 patients in group $3(20 \%)$. Fifty-two $(86.6 \%)$ out of 60 patients completed the study. The most common cause of discontinuation of the study was confusion (7 patients) (Table 2). In pain assessment according to the BPI-SF, a significant decrease in all pain intensity items and a significant improvement in all pain interference items was observed in each patient group during the study period. Detailed results of pain treatment were published (17). A report on the impact of the treatment on physical fitness is presented elsewhere (18).

The GDS-SF scores are shown in Table 3. Mean scores for women were 5.9, and for men 5.0;

Table 1. Doses of transdermal and sublingual buprenorphine used in the study in individual groups.

\begin{tabular}{|c|c|c|c|c|}
\hline \multirow{2}{*}{} & \multicolumn{2}{|c|}{ Transdermal buprenorphine } & \multicolumn{2}{c|}{ Sublingual buprenorphine } \\
\cline { 2 - 5 } & Dose range & Mean \pm standard deviation & Dose range & Mean \pm standard deviation \\
\hline Group 1 & $8.75 \mu \mathrm{g} / \mathrm{h}-52.5 \mu \mathrm{g} / \mathrm{h}$ & $20.26 \mu \mathrm{g} / \mathrm{h} \pm 14.59$ & $0.20 \mathrm{mg}-1.00 \mathrm{mg}$ & $0.43 \mathrm{mg} \pm 0.27$ \\
\hline Group 2 & $17.5 \mu \mathrm{g} / \mathrm{h}-70 \mu \mathrm{g} / \mathrm{h}$ & $27.12 \mu \mathrm{g} / \mathrm{h} \pm 14.44$ & $0.20 \mathrm{mg}-1.60 \mathrm{mg}$ & $0.62 \mathrm{mg} \pm 0.52$ \\
\hline Group 3 & $35 \mu \mathrm{g} / \mathrm{h}-52.5 \mu \mathrm{g} / \mathrm{h}$ & $43.08 \mu \mathrm{g} / \mathrm{h} \pm 9.08$ & $0.20 \mathrm{mg}-1.40 \mathrm{mg}$ & $0.42 \mathrm{mg} \pm 0.31$ \\
\hline All patients & $8.75 \mu \mathrm{g} / \mathrm{h}-70 \mu \mathrm{g} / \mathrm{h}$ & $28.60 \mu \mathrm{g} / \mathrm{h} \pm 15.89$ & $0.20 \mathrm{mg}-1.60 \mathrm{mg}$ & $0.48 \mathrm{mg} \pm 0.38$ \\
\hline
\end{tabular}

Table 2. Initial and final doses of buprenorphine used in patients who discontinued the study and causes of discontinuation.

\begin{tabular}{|c|c|c|c|c|c|}
\hline No. & $\begin{array}{c}\text { Patient } \\
\text { group }\end{array}$ & $\begin{array}{c}\text { An initial dose } \\
\text { of buprenorphine }\end{array}$ & $\begin{array}{c}\text { Dose of buprenorphine on the day } \\
\text { of discontinuation }\end{array}$ & $\begin{array}{c}\text { Day } \\
\text { of discontinuation }\end{array}$ & $\begin{array}{c}\text { Causes } \\
\text { of discontinuation }\end{array}$ \\
\hline 1 & 1 & $8.75 \mu \mathrm{g} / \mathrm{h}$ & $8.75 \mu \mathrm{g} / \mathrm{h}$ & 6 & Fever, confusion \\
\hline 2 & 3 & $35 \mu \mathrm{g} / \mathrm{h}$ & $35 \mu \mathrm{g} / \mathrm{h}$ & 2 & Confusion \\
\hline 3 & 3 & $35 \mu \mathrm{g} / \mathrm{h}$ & $52.5 \mu \mathrm{g} / \mathrm{h}$ & 6 & Confusion \\
\hline 4 & 3 & $35 \mu \mathrm{g} / \mathrm{h}$ & $35 \mu \mathrm{g} / \mathrm{h}$ & 6 & 4 \\
\hline 5 & 3 & $35 \mu \mathrm{g} / \mathrm{h}$ & $35 \mu \mathrm{g} / \mathrm{h}$ & 2 & Confusion \\
\hline 6 & 3 & $35 \mu \mathrm{g} / \mathrm{h}$ & $35 \mu \mathrm{g} / \mathrm{h}$ & 6 & Vomiting \\
\hline 7 & 3 & $35 \mu \mathrm{g} / \mathrm{h}$ & $52.5 \mu \mathrm{g} / \mathrm{h}$ & 6 & Drowsiness, confusion \\
\hline 8 & 3 & $35 \mu \mathrm{g} / \mathrm{h}$ & $35 \mu \mathrm{g} / \mathrm{h}$ & & Confusion \\
\hline
\end{tabular}

Table 3. The Geriatric Depression Scale-Short Form scores measured at baseline.

\begin{tabular}{|c|c|c|c|c|}
\hline \multirow{2}{*}{ Patient group } & \multicolumn{4}{|c|}{ The Geriatric Depression Scale-Short Form scores } \\
\cline { 2 - 5 } & Mean \pm standard deviation & $\begin{array}{c}\text { Range } \\
(0-15 \text { points })\end{array}$ & $\begin{array}{c}\text { Mild depression } \\
(6-10 \text { points }) \\
\text { N (\%) }\end{array}$ & $\begin{array}{c}\text { Severe depression } \\
(11-15 \text { points }) \\
\text { N }(\%)\end{array}$ \\
\hline Group 1 & $4.55 \pm 3.10$ & $1-11$ & $8(40 \%)$ & $4(20 \%)$ \\
\hline Group 2 & $5.85 \pm 3.19$ & $2-13$ & $9(45 \%)$ & $1(5 \%)$ \\
\hline Group 3 & $6.80 \pm 3.87$ & $0-14$ & $6(30 \%)$ & $1(5 \%)$ \\
\hline All patients & $5.73 \pm 3.47$ & $0-14$ & $23(38.3 \%)$ & $6(10 \%)$ \\
\hline
\end{tabular}

$\mathrm{N}(\%)$ - number (percentage) of patients 
Table 4. The Edmonton Symptom Assessment System-revised (ESAS-r) scores obtained on day 1 and day 10 of the study for all patients with the results of the statistical analysis.

\begin{tabular}{|c|c|c|c|c|c|}
\hline \multirow[b]{2}{*}{$\begin{array}{l}\text { ESAS-r } \\
\text { items }\end{array}$} & \multirow[b]{2}{*}{$\begin{array}{l}\text { Day } \\
\text { of the study }\end{array}$} & \multirow[b]{2}{*}{$\begin{array}{c}\text { Mean values } \pm \text { standard } \\
\text { deviation }\end{array}$} & \multicolumn{3}{|c|}{ P-values (ANOVA main effects) } \\
\hline & & & $\begin{array}{c}\text { Effect } \\
\text { of treatment }\end{array}$ & $\begin{array}{l}\text { Effect } \\
\text { of time }\end{array}$ & $\begin{array}{c}\text { Interaction of treatment } \\
\text { and time }\end{array}$ \\
\hline \multirow{2}{*}{ Pain } & Day 1 & $5.083 \pm 2.599$ & \multirow{2}{*}{0.187} & \multirow{2}{*}{$<0.001$} & \multirow{2}{*}{0.721} \\
\hline & Day 10 & $0.673 \pm 1.024$ & & & \\
\hline \multirow{2}{*}{ Fatigue } & Day 1 & $4.750 \pm 3.358$ & \multirow{2}{*}{0.255} & \multirow{2}{*}{$<0.001$} & \multirow{2}{*}{0.477} \\
\hline & Day 10 & $1.173 \pm 1.677$ & & & \\
\hline \multirow{2}{*}{ Drowsiness } & Day 1 & $4.167 \pm 3.335$ & \multirow{2}{*}{0.261} & \multirow{2}{*}{$<\mathbf{0 . 0 0 1}$} & \multirow{2}{*}{0.934} \\
\hline & Day 10 & $1.327 \pm 2.055$ & & & \\
\hline \multirow{2}{*}{ Nausea } & Day 1 & $0.267 \pm 1.103$ & \multirow{2}{*}{0.125} & \multirow{2}{*}{0.066} & \multirow{2}{*}{0.606} \\
\hline & Day 10 & $0.077 \pm 0.334$ & & & \\
\hline \multirow{2}{*}{ Vomiting } & Day 1 & $0.017 \pm 0.129$ & \multirow{2}{*}{0.176} & \multirow{2}{*}{0.581} & \multirow{2}{*}{0.702} \\
\hline & Day 10 & $0.038 \pm 0.277$ & & & \\
\hline \multirow{2}{*}{ Constipation } & Day 1 & $4.233 \pm 4.147$ & \multirow{2}{*}{0.020} & \multirow{2}{*}{$<0.001$} & \multirow{2}{*}{0.506} \\
\hline & Day 10 & $1.711 \pm 2.278$ & & & \\
\hline \multirow{2}{*}{ Lack of appetite } & Day 1 & $4.483 \pm 3.342$ & \multirow{2}{*}{0.946} & \multirow{2}{*}{$<0.001$} & \multirow{2}{*}{1.000} \\
\hline & Day 10 & $1.673 \pm 2.112$ & & & \\
\hline \multirow{2}{*}{$\begin{array}{l}\text { Shortness } \\
\text { of breath }\end{array}$} & Day 1 & $0.917 \pm 1.942$ & \multirow{2}{*}{0.799} & $<0001$ & 0024 \\
\hline & Day 10 & $0.077 \pm 0.269$ & & $<0.001$ & 0.024 \\
\hline Denreccion & Day 1 & $5.133 \pm 3.347$ & 0384 & - 0001 & 0070 \\
\hline Depression & Day 10 & $1.692 \pm 2.271$ & 0.384 & $<0.001$ & $0.9 / 0$ \\
\hline & Day 1 & $3.450 \pm 3.422$ & ר2 & $<0001$ & 0013 \\
\hline Anxiety & Day 10 & $0.865 \pm 1.645$ & 0.222 & $<0.001$ & 0.913 \\
\hline Well hoing & Day 1 & $5.483 \pm 2.143$ & 0314 & $<0001$ & 0.974 \\
\hline wen-oerng & Day 10 & $1.942 \pm 1.765$ & 0.314 & $<0.001$ & 0.914 \\
\hline
\end{tabular}

whereby a score greater than 5 (signs of depression) was reported by 29 patients (48.3\%): $25(53.19 \%)$ women and $4(30.76 \%)$ men. No significant differences were observed between categories $(p=0.1)$.

The statistical analysis of ESAS-r revealed a significant improvement in time in the evaluation of current pain (Figure 2), fatigue, drowsiness, lack of appetite, depression, anxiety, and well-being, without significant differences between patient groups (Table 4).

Regarding nausea and vomiting, no differences in time and between patient groups were observed.

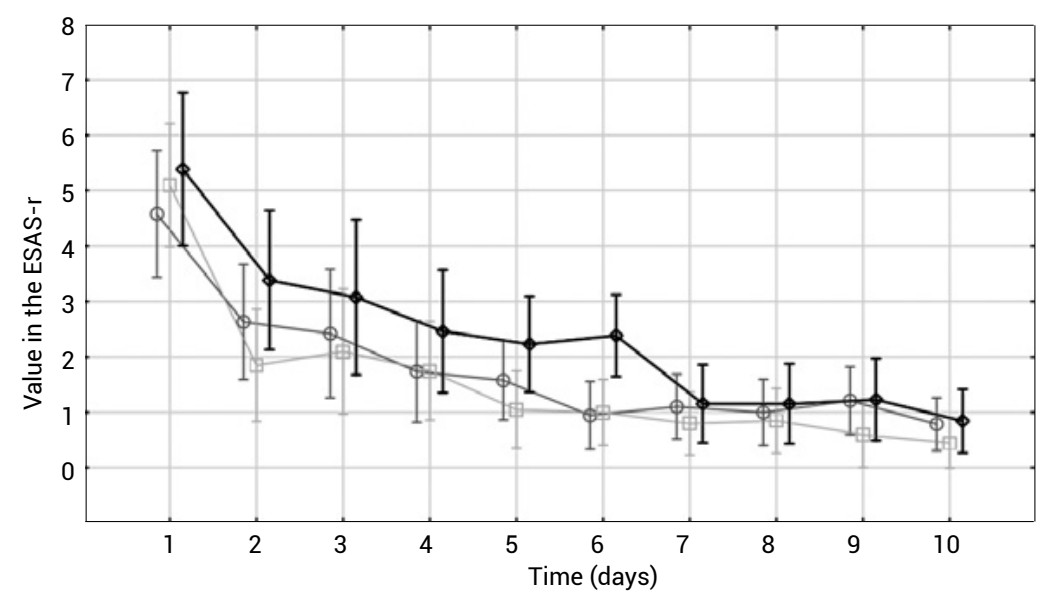

Figure 2. Pain in the ESAS-r in patient groups during 10 days of the study.

Vertical bars denote 0.95 confidence intervals. 

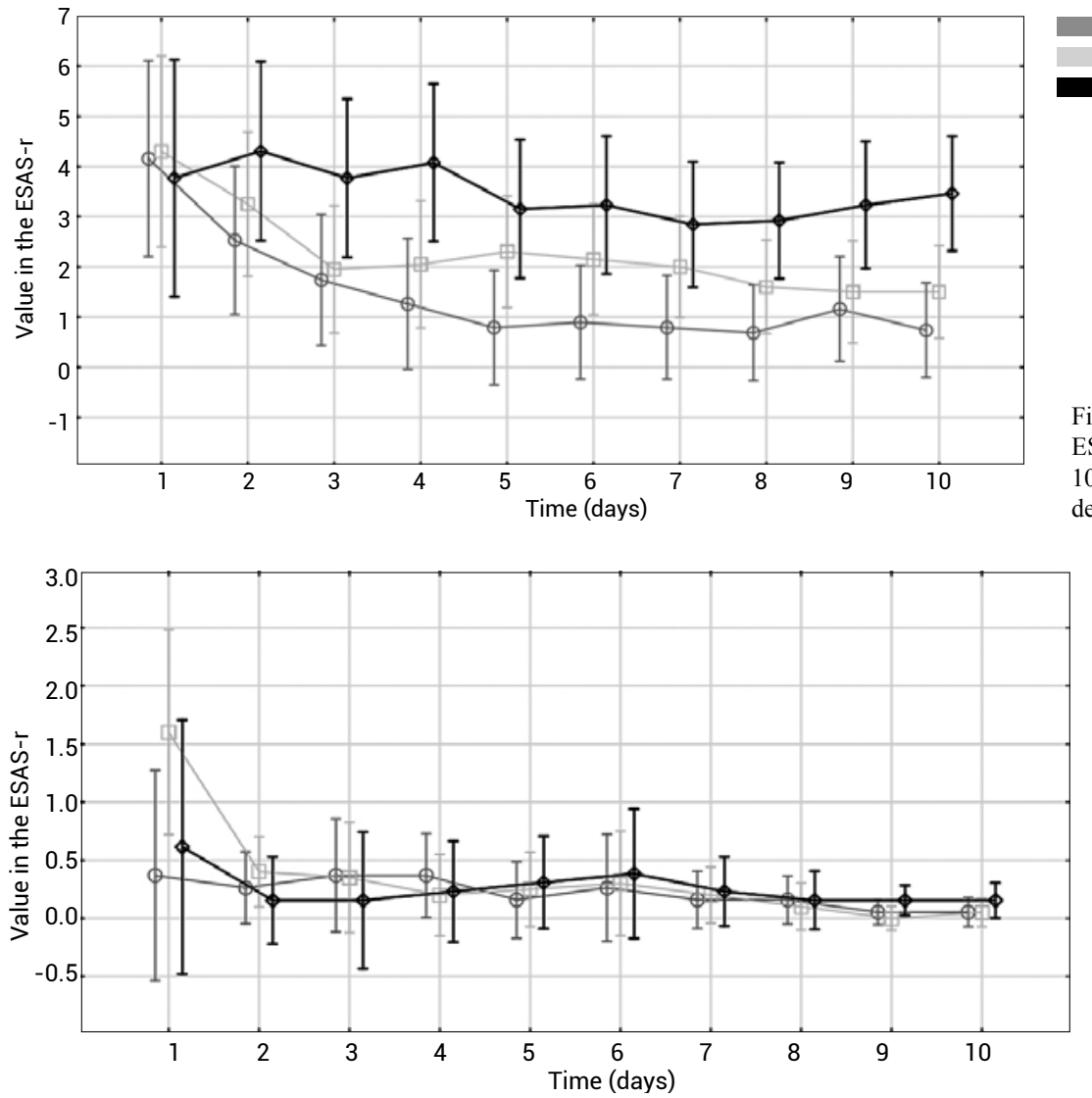

Group 1

Group 2

Group 3

Figure 3. Constipation in the ESAS-r in patient groups during 10 days of the study. Vertical bars denote 0.95 confidence intervals.

Figure 4. Shortness of breath in the ESAS- $r$ in patient groups during 10 days of the study. Vertical bars denote 0.95 confidence intervals.

However, the mean scores of these symptoms in each group were below 1.0, clinically insignificant.

In the case of constipation, an improvement was observed as well as differences between patient groups - with symptom intensity proportionate to the initial dose of buprenorphine used (Figure 3).

All patients were administered $20 \mathrm{~mL}$ of lactulose daily in the prevention of constipation, however, in $8(13.33 \%)$ patients administration of lactulose was discontinued due to the presence of single loose stools and diarrhea (5 patients in group 1; 2 patients in group 2, and 1 patient in group 3 ). However, due to the ineffectiveness of lactulose in $15(25 \%)$ patients, a further intervention was necessary. In group 1 , three patients were administered glycerin suppositories 7 times altogether and enema once; in group 2, six patients were administered glycerin suppositories 17 times and enema 3 times altogether; and in group 3, six patients were administered glycerin suppositories 12 times and enema twice altogether. In group 1, antiemetics were not used; in group 2, two patients were administered antiemetics as needed 3 times; and in group 3, five patients ten times.

During the study period, other symptoms were reported by 3 patients in group 1 (diarrhea),
2 patients in group 2 (diarrhea and itching), and 3 patients in group 3 (diarrhea, itching, and dizziness). In the case of shortness of breath, an improvement in time was obtained for all the groups, and in group 2, an initial improvement was observed (Figure 4).

\section{DISCUSSION}

In this study, the quality of life of elderly patients diagnosed with osteoarthritis during treatment of chronic pain with transdermal buprenorphine was evaluated. Patients qualified for the study and randomized for individual groups did not differ with respect to their age, sex, place of residence, education, and concurrent diseases. Evaluation of symptoms such as pain, fatigue, drowsiness, nausea, vomiting, constipation, lack of appetite, shortness of breath, depression, anxiety, well-being and other symptoms were conducted in the ESAS-r. An improvement was observed for all symptoms except for nausea and vomiting during 10 days.

It should be noted that among the patients who did not complete the study, 7 out of 8 patients who started treatment at an initial dose of $35 \mu \mathrm{g} / \mathrm{h}$ confusion, drowsiness and vomiting appeared at different 
times since the beginning of the treatment, which made the continuation of the study impossible. Confusion was observed in the remaining person who started treatment at $8.75 \mu \mathrm{g} / \mathrm{h}$, yet during fever which may have increased transdermal drug absorption. It can be assumed that using lower initial doses of buprenorphine $(8.75 \mu \mathrm{g} / \mathrm{h} ; 17.5 \mu \mathrm{g} / \mathrm{h})$ may reduce the incidence and intensity of adverse effects, which may lead to discontinuation of treatment. This hypothesis, however, needs further studies with a larger group of patients, especially the elderly (19-21). Out of 8 patients who did not complete the study 7 patients displayed symptoms of delirium (confusion, drowsiness) after starting treatment with buprenorphine. This is a significant percentage considering the fact that patients with good MMSE results were enrolled in the study. Opioids may be a contributing factor of cognitive impairment and pose a risk in dementia patients who were not enrolled in this study. As many geriatric patients have dementia, this suggests administration of lower initial doses and more careful opioid titration in this patient group (22). Another problem might be difficulties in pain assessment and in consequence undertreatment of pain in patients diagnosed with dementia (23).

Chronic pain causes several negative consequences such as sleep disturbance, drowsiness during the day, decreased concentration, anxiety, depression, lack of appetite and decreased routine activity, and may lead to social withdrawal and interferes with everyday activities in any other way. As a result, patients with chronic pain find themselves in a vicious circle where psychological and social factors complicate their physical condition. Therefore, it is not surprising that the implementation of effective analgesic treatment improves accompanying symptoms (24). Consequently, obtaining functional improvement compensates for possible negative consequences of using opioids (14). This concerns both mental (fatigue, drowsiness, anxiety, depression) as well as general functions (wellbeing, shortness of breath). The exception remains adverse gastrointestinal effects of opioids such as constipation, nausea, vomiting, dry mouth, gastroesophageal reflux, abdominal cramps, and bloating, which are jointly referred to as opioid-induced bowel dysfunction (OIBD) (25). OIBD is induced by the impact of opioids both on central (influence on the spinal cord and supraspinal sites) and peripheral opioid receptors (through $\mu$ and $\kappa$ receptors located in the muscular membrane and the plexus of the muscular layer of the gastrointestinal tract) that slow down gastrointestinal motility. Tolerance does not develop for these symptoms which means that they are persistent and frequently progressive and, therefore, require active medical procedures preventing their prevalence and progression (26). Elderly and palliative care patients are shown to be most at risk of adverse effects of opioids in the gastrointestinal system. Among the above-mentioned symptoms, opioid-induced constipation (OIC) is the most frequently reported and persisting adverse effect in patients receiving opioids.

Regarding nausea and vomiting no improvement in time in ESAS-r was demonstrated. However, it should be noted that except for one patient who resigned from the study due to extensive vomiting, adverse effects increased slightly in the remaining patients, with the mean value below 1 in individual groups. Also, the differences between patient groups with respect to this aspect were not significant, although the use of rescue antiemetics was higher in groups with higher initial doses of buprenorphine.

In contrast, in the case of constipation, an improvement both in successive measurements in time and between individual groups was observed, with the intensity of constipation directly proportional to the dose of buprenorphine used. There is, indeed, a correlation between a total dose of an opioid and the severity of constipation, which was also shown in the present study (27). OIBD does not show tolerance and requires active medical procedures preventing a progression of symptoms. Lactulose used prophylactically was effective in the majority of patients, although 15 patients $(25 \%)$ required further interventions with the use of glycerin suppositories or enema due to the ineffectiveness of lactulose. Interventions were more necessary in the groups using higher doses of buprenorphine. It should be stressed, however, that adverse effects of buprenorphine on the gastrointestinal system are milder compared to other opioids (28). In addition, other causes of the intensification of constipation should be taken into account in patients receiving opioids, which are a result of older age, dietary restrictions, lack of physical activity, dehydration, and polypharmacy, thus, the management of constipation should be comprehensive.

An improvement with respect to shortness of breath in ESAS-r, is worth noticing, in the comparison of individual measurements in time and between groups, particularly on day 1 of the study. Dyspnea may be induced by concurrent diseases, in particular cardiac insufficiency. It is interesting that buprenorphine displays a ceiling effect on the possibility of inducing respiratory depression. However, when using therapeutic doses of 
the drug, respiratory rate, and blood oxygen saturation are slightly decreased. In a study that compared buprenorphine with fentanyl in healthy volunteers, these parameters reached a plateau at the level of half of the initial values and did not decrease after further repeated increased doses of buprenorphine; however, during the administration of fentanyl, a further increase of the dose caused the respiratory arrest. The analgesic effect curves were proportionate to buprenorphine doses used which indicates a ceiling effect in respiratory depression, but not in analgesia in the range of the doses used $(29,30)$.

An improvement in time in depression and anxiety of ESAS-r was showed. This effect was also observed in patients with and without signs of depression in the GDS-SF. It can be assumed that effective pain treatment reduces in itself a negative impact of pain symptoms on the psychological state, regardless of coexisting changes connected with depression. This shows that buprenorphine analgesia far outweighs its potential inhibiting influence on serotonin and dopamine release. Such a minor clinical impact on mood disorders is vital for patients with coexisting symptoms of depression (31). In geriatric departments, depression is generally described in approximately $50 \%$ of hospitalized patients. In the studied population, a similar result was obtained, although patients with features of dementia were not qualified for the study. There is a significant influence of depressive syndrome on the cognitive functions in the elderly (32).

In a prospective cohort study prevalence of depression, similar to chronic pain, increased with age (33). This is one of the premises that indicate an association between these chronic pathologies in the elderly. Chronic pain is a frequent symptom in patients with depression. On the other hand, patients suffering from chronic pain are at higher risk for depression. Data from literature is, however, inconclusive. It is estimated that depression affects from $5-85 \%$ of patients with chronic pain and $65 \%$ of persons with depression have at least one pain condition (34). According to other epidemiological studies, it may be assumed that chronic pain increases the risk of depression 2.5 to 4.1 times $(35,36)$. With the comorbidity of chronic pain and depression, patients report higher intensity of pain, experience lower pain tolerance, and diminished ability to cope with pain. Such persons are more frequently disabled and more prone to a lower evaluation of the quality of life in comparison to persons suffering from chronic pain or depression only (37).
In a large Pol-Senior study, which also used the GDS-SF as a tool, clinically significant depressive symptoms were found in $29.7 \%$ of persons over 65 years old. Depressive symptoms occurred more frequently and with higher intensity in the oldest-old ( 80 years old and more) than in younger (65-79 years old) $-35.1 \%$ and $26.1 \%$, respectively. Women were more frequently diagnosed with depression than men - in early old age, depressive symptoms were found in $31.7 \%$ of women and $20.7 \%$ of men, and in the oldest-old in over $40 \%$ of women and almost $30 \%$ of men. More than one-third of patients complaining about pain had symptoms of depression against one-fourth of those not complaining about pain (38). The present study confirmed greater comorbidity of depression in women $(57.44 \%)$ compared to men $(30.76 \%)$. However, differences between individual age groups were not observed. No differences in the prevalence of depression in the elderly between individual age categories, particularly in the oldest-old were also described by other authors $(39,40)$. Pain intensity is also believed to be strongly associated with depression in the elderly, whereas in the young this connection is not visible. Both conditions occur more commonly in women, who more frequently suffer from chronic pain if diagnosed with depression (41).

It is estimated that about $40 \%$ of cases of depression in persons over 65 years old are unrecognized for various reasons. Core symptoms of depression in the elderly are often overlooked. The most important of these are complaints about somatic symptoms and cognitive impairment which often accompany the aging process and are underestimated by the patients, environment, and medical staff. Therefore, a screening test for depression is recommended in the elderly, particularly in patients complaining about chronic pain. This is crucial because effective treatment of depression in the elderly can improve not only their mental state but also their physical functioning (42).

A reduction in the intensity of pain in ESAS-r was obtained with the use of transdermal buprenorphine (baseline pain treatment) and buprenorphine sublingual tablets (breakthrough pain management). It is worth noting that the initial and average doses of transdermal buprenorphine were low (an average dose in all the patients was $28.6 \mu \mathrm{g} / \mathrm{h}$ ). This is in line with reports about the beneficial effect of lower doses of transdermal buprenorphine $(5 \mu \mathrm{g} / \mathrm{h} ; 10 \mu \mathrm{g} / \mathrm{h}$ and $20 \mu \mathrm{g} / \mathrm{h}$ ) than those available in Poland (the lowest dose is $35 \mu \mathrm{g} / \mathrm{h}$ ), particularly in the elderly population $(20,21)$. Despite 
the intense pain, patients qualified for the study used buprenorphine sublingual tablets as needed to a limited extent. The mean value for all the patients was $0.48 \mathrm{mg}$ per person during 10 days, i.e. slightly more than two $0.2 \mathrm{mg}$ tablets. Therefore, it should be assumed that transdermal buprenorphine was of vital importance in the observed reduction of baseline pain intensity.

Transdermal buprenorphine shows many advantages that make this drug a preferred opioid in the treatment of moderate and intense chronic pain in the elderly. In comparison to other opioids, buprenorphine is characterized by a smaller risk of adverse effects such as cognitive impairment, OIBD, in particular, OIC; immunosuppression, and endocrinopathy as well as respiratory depression. Buprenorphine is an effective and safe opioid analgesic in elderly patients also with respect to changes in metabolism and renal changes. A small risk of drug interaction and drug dependence also support the selection of buprenorphine in this group of patients (19).

Limitations of the study include a modest study sample, patients recruited in a single-center, relatively short period of the study, and including patients without diagnosis of dementia. However, to the best of our knowledge, this is a first study investigating the impact of transdermal buprenorphine treatment with different starting doses on the quality of life of elderly patients with severe chronic pain induced by osteoarthritis.

\section{CONCLUSIONS}

Transdermal buprenorphine decreased symptom intensity such as pain, fatigue, drowsiness, lack of appetite, shortness of breath, depression, anxiety, and well-being. Treatment tolerance was better with lower initial doses of transdermal buprenorphine $8.75 \mu \mathrm{g} / \mathrm{h}$ and $17.5 \mu \mathrm{g} / \mathrm{h}$ compared to a dose of $35 \mu \mathrm{g} / \mathrm{h}$. Transdermal buprenorphine in the treatment of chronic pain of severe intensity in elderly patients diagnosed with osteoarthritis provided a significant reduction of pain intensity regardless of the initial dose used.

\section{Funding}

The study has no funding.

\section{Conflicts of interest}

The authors declare that there are no conflicts of interest.

\section{REFERENCES}

1. Kress H.G., Ahlbeck K., Aldington D., Alon E., Coaccioli S., et al.: Curr. Med. Res. Opin. 30, 1153 (2014).

2. Rastogi R., Meek B.D.: Clin. Interv. Aging 8, 37 (2013).

3. Wojszel Z.B., Magnuszewski L.: Diabetes Metab. Syndr. Obes. 13, 4599 (2020).

4. Gibson S.J., Lussier D.: Pain Med. 13 Suppl 2, S23 (2012).

5. Abdulla A., Bone M., Adams N., Elliott A.M., Jones D., et al.: Age Ageing 42, 151 (2013).

6. Malec M., Shega J.W.: Med. Clin. North Am. 99, 337 (2015).

7. Mattenklodt P., Leonhardt C.: Schmerz 29, 349 (2015).

8. Jones M.R., Ehrhardt K.P., Ripoll J.G., Sharma B., Padnos I.W., et al.: Curr. Pain Headache Rep. 20, 9 pages (2016).

9. Gianni W., Madaio R.A., Di Cioccio L., D’Amico F., Policicchio D., et al.: Arch. Gerontol. Geriatr. 51, 273 (2010).

10. Bernabei R., Gambassi G., Lapane K., Landi F., Gatsonis C., et al.: JAMA 279, 1877 (1998).

11. Reid M.C., Bennett D.A., Chen W.G., Eldadah B.A., Farrar J.T., et al.: Pain Med. 12, 1336 (2011).

12. Podichetty V.K., Mazanec D.J., Biscup R.S.: Postgrad. Med. J. 79, 627 (2003).

13. Gianni W., Madaio A.R., Ceci M., Benincasa E., Conati G., et al.: J. Pain Symptom Manage. 41, 707 (2011).

14. Chapman S.L., Byas-Smith M.G., Reed B.A.: Clin. J. Pain 18, 83 (2002).

15. Hannon B., Dyck M., Pope A., Swami N., Banerjee S., et al.: J. Pain Symptom Manage. 49, 945 (2015).

16. Albiński R., Kleszczewska-Albińska A., Bedyńska S.: Psychiatr. Pol. 45, 555 (2011) (in Polish).

17. Widenka M., Leppert W.: J. Physiol. Pharmacol. 71, 739 (2020).

18. Widenka M., Leppert W.: Ból 22, 53 (2021).

19. Davis M.P.: J. Support. Oncol. 10, 209 (2012).

20. Plosker G.L., Lyseng-Williamson K.A.: CNS Drugs 26, 367 (2012).

21. Uberall M.A., Müller-Schwefe G.H.: Curr. Med. Res. Opin. 28, 1585 (2012).

22. Wojszel Z.B.: Clin. Interv. Aging 15, 2183 (2020).

23. Brecher D.B., West T.L.: Am. J. Hosp. Palliat. Care 33, 276 (2016). 
24. Perez J., Olivier S., Rampakakis E., Borod M., Shir Y.: Pain Res. Manag. 2016,7 pages (2016).

25. Panchal S.J., Müller-Schwefe P., Wurzelmann J.I.: Int. J. Clin. Pract. 61, 1181 (2007).

26. Holzer P., Ahmedzai S.H., Niederle N., Leyendecker P., Hopp M., et al.: J. Opioid. Manag. 5, 145 (2009).

27. Villars P., Dodd M., West C., Koetters T., Paul S.M., et al.: J. Pain. Symptom. Manage. 33, 67 (2007).

28. Müller-Lissner S., Bassotti G., Coffin B., Drewes A.M., Breivik H., et al.: Pain Med. 18, 1837 (2017).

29. Dahan A., Yassen A., Bijl H., Romberg R., Sarton E., et al.: Br. J. Anaesth. 94, 825 (2005).

30. Dahan A., Yassen A., Romberg R., Sarton E., Teppema L., et al.: Br. J. Anaesth. 96, 627 (2006).

31. Budd K., Collett B.J.: Br. J. Anaesth. 90, 722 (2003).

32. Wojszel Z.B., Kasiukiewicz A., Magnuszewski L.: J. Nutr. Health Aging 23, 509 (2019).

33. Solhaug H.I., Romuld E.B., Romild U., Stordal E.: Int. Psychogeriatr. 24, 151 (2012).
34. Bair M.J., Robinson R.L., Katon W., Kroenke K.: Arch. Int. Med. 163, 2433 (2003).

35. McCarthy L.H., Bigal M.E., Katz M., Derby C., Lipton R.B.: J. Am. Geriatr. Soc. 57, 115 (2009).

36. Bauer H., Emeny R.T., Baumert J., Ladwig K.H.: Eur. J. Pain 20, 1253 (2016).

37. Sternke E.A., Abrahamson K., Bair M.J.: Pain Manag. Nurs. 17, 363 (2016).

38. Mossakowska M., Więcek A., Błędowski P.: Aspekty medyczne, psychologiczne, socjologiczne i ekonomiczne starzenia się ludzi w Polsce. Termedia Wydawnictwo Medyczne, Poznań 2012 (in Polish).

39. Stek M.L, Gussekloo J., Beekman A.T., van Tilburg W., Westendorp R.G.: J. Affect. Disord. 78, 193 (2004).

40. Wild B., Herzog W., Schellberg D., Lechner S., Niehoff D., et al.: Int. J.. Geriatr. Psychiatry 27, 375 (2012).

41. Scherer M., Hansen H., Gensichen J., Mergenthal K., Riedel-Heller S., et al.: BMC Fam. Pract. 17, 8 pages (2016).

42. Callahan C.M., Kroenke K., Counsell S.R., Hendrie H.C., Perkins A.J., et al.: J. Am. Geriatr. Soc. 53, 367 (2005). 